\title{
ЗАТРАТЫ НА ТРУДОВЫЕ РЕСУРСЫ: КЛАССИФИКАЦИЯ И МЕТОДИКА УПРАВЛЕНЧЕСКОГО УЧЁТА В БЕЛОРУССКОЙ ПРАКТИКЕ
}

\author{
(c) 2020 Галкина Марина Николаевна \\ ассистент кафедры финансового менеджмента \\ Полесский государственный университет, Республика Беларусь, Пинск \\ E-mail: gal.79@mail.ru \\ (c) 2020 Бухтик Марина Игоревна \\ кандидат экономических наук, доцент кафедры финансового менеджмента \\ Полесский государственный университет, Республика Беларусь, Пинск \\ E-mail:marina_buhtik@mail.ru
}

\section{(c) 2020 Киевич Александр Владимирович}

доктор экономических наук, профессор кафедры финансового менеджмента

Полесский государственный университет, Республика Беларусь, Пинск

E-mail: a.v.kievich@yandex.ru

В статье предложена классификация затрат на трудовые ресурсы по функциональному назначению, структурным подразделениям, частоте совершения и в зависимости от источников их финансирования. А с целью формирования и обобщения информации о сумме затрат на трудовые ресурсы организаций авторами предложено использование отдельных синтетических и аналитических счетов.

Ключевые слова: трудовые ресурсы, затраты на трудовые ресурсы, классификация трудовых ресурсов, вознаграждения, управленческий учёт.

Как нам известно, затраты корпораций в значительной степени связаны с оптимальным количеством работников и повышением их эффективности. Многие организации осознают этот факт и считают, что лучше иметь меньше работников, но зато более высокой квалификации. Они стараются удержать «ключевых» работников, а на временной основе нанимают (арендуют) других работников. Но с другой стороны, существует многожество организаций, которые не понимают, какие работники для них являются ключевыми. Успешные - приспосабливают трудовые ресурсы к своим потребностям - используют временную рабочую силу (персональный лизинг) и избавляются от видов деятельности (и соответственно, кадров), которые не считают жизненно необходимыми для своей деятельности [1].

Несмотря на большое количество научных разработок в области классификации трудовых ресурсов и их признаков, полноценного исследования, посвященного классификации затрат на трудовые ресурсы в Республике Беларусь (РБ) не существует.

Для эффективной организации управленче- ского учёта затрат на трудовые ресурсы необходимо применять экономически обоснованную их классификацию по определенным признакам, что позволит правильно учитывать затраты на трудовые ресурсы, анализировать их на микроуровне, проводить их детальный управленческий аудит [2]. В связи с этим авторами разработана классификация затрат на трудовые ресурсы по их функциональному значению и представлена на рисунке 1.

По нашему мнению в состав затрат по функциональному значению необходимо отнести:

1. Затраты на развитие трудовых ресурсов - затраты на обучение сотрудников, переподготовку, повышение квалификации, по участие в семинарах и конференциях.

Сегодня многие организации начали вкладывать существенные средства в образование своих сотрудников, понимая, что это всегда окупиться [3]. Такие затраты они считают так же и мощным мотивационным фактором, хорошей возможностью профессионального роста для перспективных работников. Затраты на трудовые ресурсы являются довольно дорогостоящим занятием, но экономия на них позволяет 


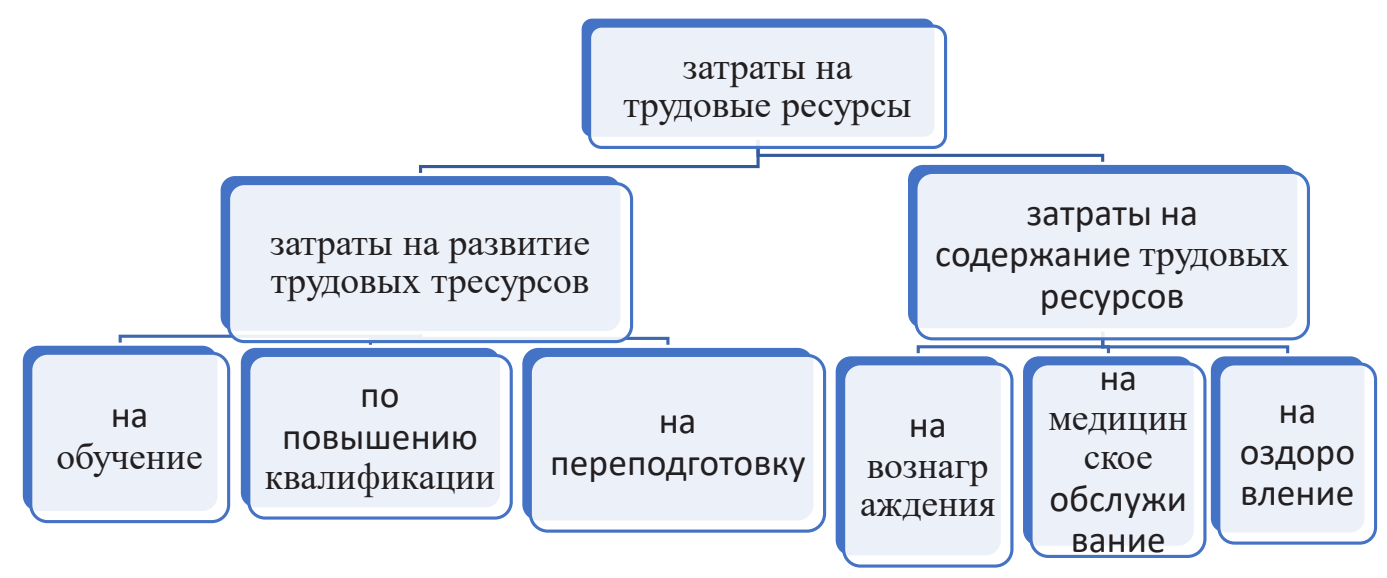

Puc. 1. Классификация затрат на трудовые ресурсы по функциональному значению Источник: собственная разработка

выиграть только в краткосрочной перспективе. Целенаправленное повышение образовательного уровня своих сотрудников - это основной фактор конкурентоспособности на современном динамически развивающемся рынке.

Проведение обучения персонала на рабочем месте важно и тем, что персоналу никуда не надо отрываться со своего рабочего места, потому что предоставляется возможность обучаться там, где человек работает, и сразу применять свои знания. В научной литературе рассматривается и процесс морального старения накопленного научно-образовательного потенциала персонала. Поэтому данный вид износа замедляется посредством затрат на повышение квалификации.

2. Затраты на содержание трудовых ресурсов.

К этой группе необходимо отнести затраты корпорации на:

А) вознаграждения трудовых ресурсов

Для учёта вознаграждений работникам в РБ практике учёта в РБ, согласно типового плана счетов, используется синтетический счёт 70 «Расчёты с персоналом по оплате труда» без выделения субсчетов [4].

Анализируя нормативно законодательные акты Российской Федерации, мы видим, что в типовом плане счетов и Инструкции по его применению, выделение субсчетов к счёту 70 «Расчёты с персоналом по оплате труда» также не рекомендуется [5].

Изучив план счетов Украины, мы видим, что для учёта расчётов по заработной плате используется счёт 66 «Расчёты по оплате труда», который предназначен для учёта расчётов по всем видам оплаты труда: заработной платы, премий, исполнения общественных обязанностей [6]. Однако для учёта расчётов по оплате труда используют субсчета:

№ 661 «Расчёты по заработной плате»,

№ 662 «Расчёты с депонентами».

По кредиту субсчёта 661 «Расчёты по заработной плате» отражается, начисленная заработная плата всему персоналу предприятия. По дебету субсчёта 661 «Расчёты по заработной плате» отражается выплаченная заработная плата, депонированная заработная плата, удержанный подоходный налог, удержанные алименты и другие отчисления согласно исполнительным листам, отчисления в Пенсионный фонд, профсоюзные взносы, выплаченные дивиденды по акциям, суммы по больничным листам, сбор на случай безработицы, \% в фонд страхования в связи с временной нетрудоспособностью.

По дебету субсчёта 662 «Расчёты с депонентами» отражаются выплаты депонированных сумм. По кредиту субсчёта 662 «Расчёты с депонентами» отражаются суммы своевременно не выданной заработной платы, премий, пособий и т.д.

По мнению Шестак О.Н. к счёту 70 «Расчёты с персоналом по оплате труда» необходимо открыть следующие субсчёта [7]:

Субсчёт 1 «Расходы, включаемые в фонд заработной платы»,

Субсчёт 2 «Прочие расходы по содержанию трудовых ресурсов».

Согласно предложений Лосникова Р.П., к счёту 70 «Расчёты с персоналом по оплате труда» необходимо открыть следующие субсчета [8]: 
субсчёт 1 «Оплата труда за объём выполненных работ и отработанное время»; субсчёт 2 «Доплаты и надбавки»; субсчёт 3 «Премии»; субсчёт 4 «Оплата за неотработанное время»; субсчёт 5 «Прочие»; субсчёт 6 «Натуральная оплата».

Для совершенствования бухгалтерского учёта расчётов с персоналом по оплате труда некоторые авторы считают необходимым ввести систему субсчетов к счёту 70 «Расчёты с персоналом по оплате труда», отражающие расчёты со всеми категориями работников организации. Целесообразно выделить при этом субсчета, в соответствии с видом документа, на основании которого работник функционирует в корпорации:

70-1 «Расчёты со штатными работниками»,

70-2 «Расчёты с совместителями»,

70-3 «Расчёты по трудовым соглашениям»,

70-4 «Расчёты по договорам гражданскоправового характера».

Информация о расчётах с персоналом сгруппированная по такому принципу более полно отражает данные аналитического учёта. Это уменьшит вероятность совершения ошибки при переносе данных на синтетические счета. Данные субсчета позволят проанализировать структуру вознаграждений персонала, выявить резервы под снижение расходов на оплату труда и таким образом снизить себестоимость продукции, работ, услуг, поскольку эти расходы включаются в себестоимость.

При изучении автором порядка учёта расчётов по оплате труда, установлено, что согласно МСФО к счёту 70 «Расчёты с персоналом по оплате труда» выделяется также субсчёт «Расчёты по доходам от участия».

При изучении нами порядка учёта расчётов по оплате труда в некоторых организациях РБ, мы видим, что выделяются к счёту 70 «Расчёты с персоналом по оплате труда» также субсчета «Расчёты по доходам от участия».

Детально изучив нормативно законодательную базу РБ по учёту расчётов с персоналом по оплате труда, нами было выявлено, что в соответствии с Инструкцией по применению Типового плана счетов бухгалтерского учёта, по счёту 70 «Расчёты с персоналом по оплате труда» рекомендуется отражать информацию «также по выплате доходов по акциям данной организации».

Анализируя далее законодательство РБ, мы пришли к выводу, что в Инструкцию по приме- нению Типового плана счетов бухгалтерского учёта целесообразно внести изменения, связанные с учётом расчётов по оплате труда в части начисляемых дивидендов, их следует отражать только на счёте 75 «Расчёты с учредителями», субсчёт 2 «Расчёты по доходам». Это связано с тем, что искажается название счёта 70 «Расчёты с персоналом по оплате труда». Предполагается, что на нём должны отражаться операции только по начислениям различных видов оплат как вознаграждение за фактически выполненную работу (ст. 57 Трудового кодекса Республики Беларусь) [9].

Изучив предлагаемые подходы по учёту расчётов с персоналом по оплате труда в РБ, а также возникающие противоречия в нормативно правовой базе, нами предлагается введение в практику учёта требований международных стандартов финансовой отчётности [10]. Прежде всего, наименование счёта 70 «Расчёты с персоналом по оплате труда» не соответствует ни международным стандартам, ни экономической сущности данной категории «оплата труда», представляющей собой систему отношений. По мнению авторов, следует заменить термин «оплата труда» на «вознаграждение работникам», т.е. наименование счёта 70 «Расчёты с персоналом по оплате труда» на «Расчёты с работниками по вознаграждениям». Такое название счёта будет более полно и точно раскрывать его содержание, что будет способствовать улучшению организации учёта вознаграждений, детализации информации, содержащейся в регистрах синтетического и аналитического учёта, которые являются значимым источником для формирования отчётности.

Авторами предлагается открыть следующие субсчета к счёту 70 «Расчёты с персоналом по оплате труда»:

Субсчёт 1 «начисления, включаемые в фонд оплаты труда»,

Субсчёт 2 «начисления за счёт финансовых результатов»,

Субсчёт 3 «начисления из фонда социальной защиты населения».

Б) затраты на медицинское обслуживание трудовых ресурсов корпорации. К этой группе необходимо отнести затраты на оказание медицинской помощи работникам в результате ухудшения здоровья (медицинские препараты и инъекции), а также на профилактические мероприятия (вакцинация), обязательные медосмот- 
ры с целью выявления на ранних стадиях профессиональных заболеваний

В) затраты по оздоровлению персонала, что обеспечивает улучшение их здоровья и трудоспособности. К этой группе необходимо отнести затраты организации на приобретение путёвок в дома отдыха, санатории, профилактории.

Затраты на трудовые ресурсы по структурным подразделениям нам представляется возможным классифицировать образом, представленным на рис. 2 .

Учитывая международный опыт оценки трудовых ресурсов, мы также считаем целесообразным затраты на трудовые ресурсы классифицировать в зависимости от частоты их совершения на разовые и постоянные (рис. 3).

На наш взгляд, все затраты на трудовые ресурсы условно можно также разделить по источ- никам их финансирования:

1. средства бюджета - это затраты на образование в учебных заведениях,

2. средства организации, сотрудником которой является конкретный человек (затраты на переподготовку, повышения квалификации, дополнительное обучение),

3. средства самих трудовых ресурсов.

Рекомендуемая нами детализация затрат позволит подсчитать сумму затрат как в общем по организации, так и по каждому работнику, подразделению в отдельности, а также по источникам их покрытия, провести управленческий аудит этих затрат, проанализировать их эффективность.

Наличие широкого понятийного аппарата, необходимость однозначности в изложенных подходах к сущности категории «затраты на

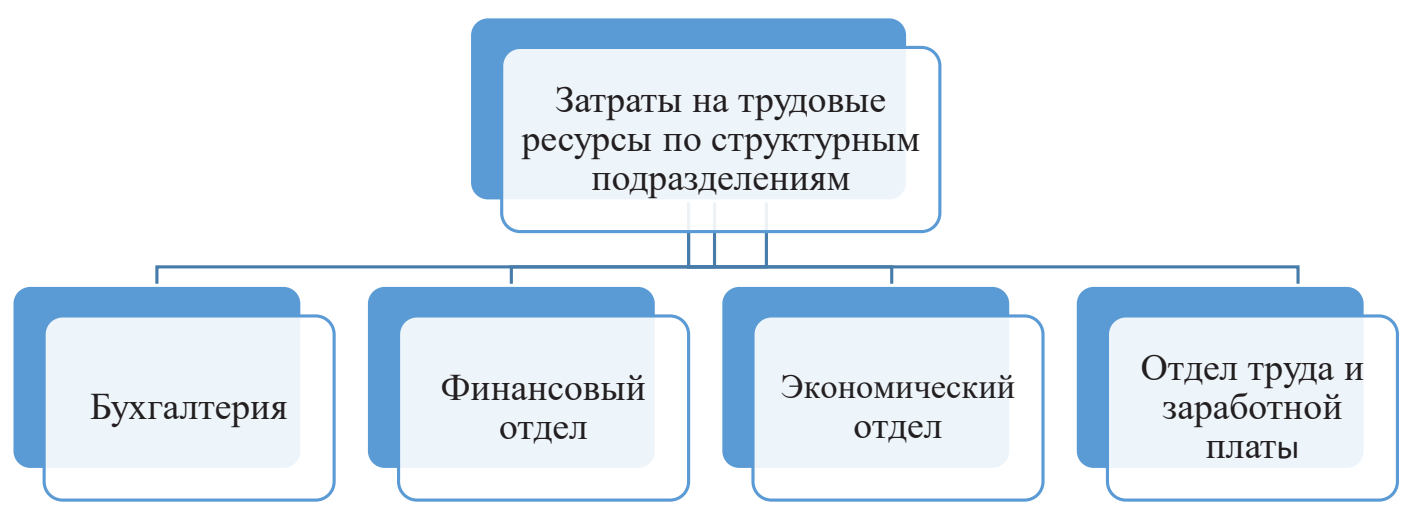

Puc. 2. Классификация затрат на трудовые ресурсы по структурным подразделениям Источник: собственная разработка

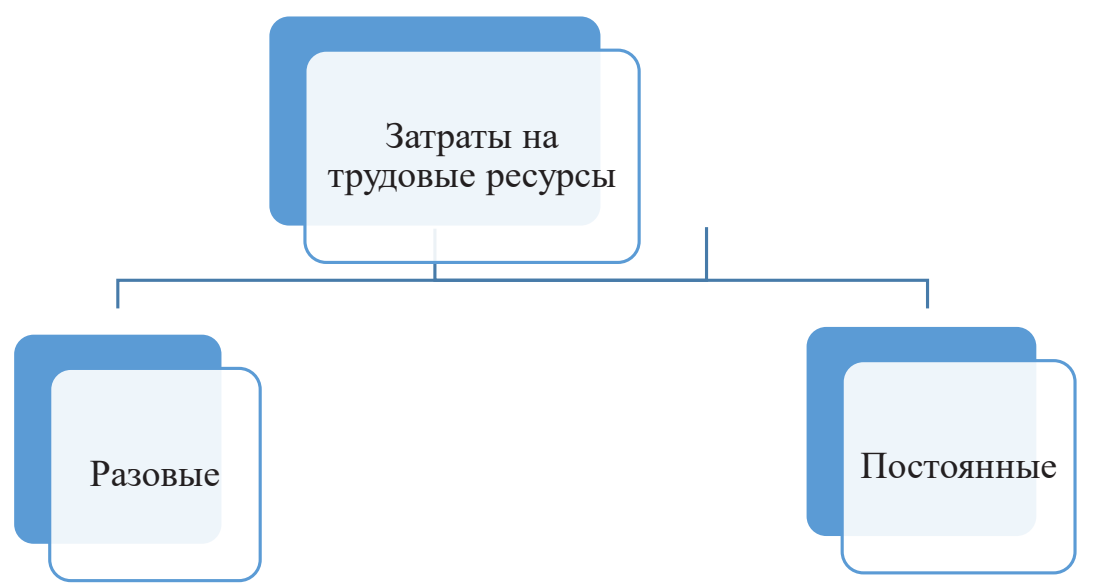

Рuc. 3. Классификация затрат на трудовые ресурсы по частоте их совершения Источник: собственная разработка 


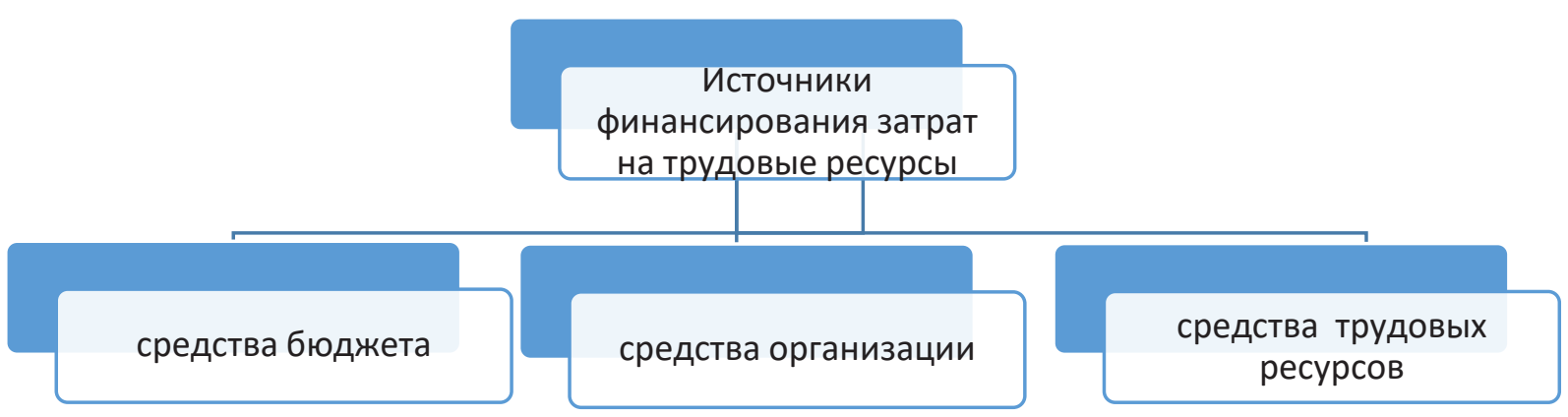

Puc. 4. Источники финансирования затрат на трудовые ресурсы Источник: собственная разработка

трудовые ресурсы» и их классификации, требует разработки методических рекомендаций по управленческому учёту, отчётности и анализу затрат на трудовые ресурсы. Здесь отметим, что современная методика отечественного управленческого и бухгалтерского учёта не предусматривает в типовом плане счетов отдельных счетов для отражения операций по затратам на трудовые ресурсы.

С целью правильного выделения счетов и субсчетов для повышения проз-рачности информации по затратам на трудовые ресурсы нами были изучены различные подходы экономистов Республики Беларусь, Российской Федерации, Украины. И по мнению многих авторов, трудовые ресурсы, по своей экономической сущности, соответствуют долгосрочным активам, однако не имеют материально вещественной формы и не подлежат амортизации. В то время как большая часть ресурсов представлена материальными объектами, стоимость которых со временем снижается посредством амортизации, а ценность людских ресурсов с годами может и должна возрастать.

Таким образом, как для блага самой организации, так и для личного блага служащих своей организации, руководство должно постоянно работать над повышением потенциала кадров. Следовательно, для их учёта невозможно применять счета, предназначенные для учёта нематериальных активов и основных средств.

Отметим, что существующая система счетов бухгалтерского учёта в РБ, не в полной мере, отражает информацию о затратах на трудовые ресурсы В настоящее время все затраты корпораций, связанные трудовыми ресурсами учитываются на разных счетах затрат во втором раз- деле баланса, в составе краткосрочных активов, что затрудняет возможность оперативного получения информации о них. Так, информация о затратах на обучение работников и повышение их квалификации, отражается на счетах 25 «Общепроизводственные расходы» и 26 «Общехозяйственные расходы», а информация о затратах на медицинское обслуживание сотрудников в собственных медицинских пунктах на счёте 29 «Обслуживающие производства и хозяйства». Большая часть информации о затратах на трудовые ресурсы в части их вознаграждений, формируется по данным счёта 70 «Расчёты с персоналом по оплате труда» из данных бухгалтерского учёта, что снижает её оперативность.

В связи с этим, для целей оперативного управленческого учёта затрат на трудовые ресурсы, по нашему мнению, целесообразно применять единую систему управленческих счетов. И с целью формирования и обобщения информации о сумме затрат на трудовые ресурсы в системе управленческого учёта корпораций предлагаем использовать счёт 27 «Затраты на трудовые ресурсы» (рисунок 5). По дебету этого счёта необходимо отражать суммы затрат, предназначенных для развития и содержания трудовых ресурсов. По кредиту - списание затрат равными долями в течение срока контракта.

К счёту 27 «Затраты на трудовые ресурсы» нами видится правильным открывать субсчета в соответствии с целевой направленностью расходования средств организации на трудовые ресурсы:

27-1 затраты на развитие трудовых ресурсов;

27-2 затраты на содержание трудовых ресурсов; 
Счёт 27 «Затраты на трудовые ресурсы»

\begin{tabular}{|l|l|}
\hline \multicolumn{1}{|c|}{ Дебет } & \multicolumn{1}{|c|}{ Кредит } \\
\hline $\begin{array}{l}\text { Начальное сальдо отражает сумму затрат на начало } \\
\text { отчётного периода }\end{array}$ & \\
Оборот дебетовый отражает общую сумму затрат на & \\
$\begin{array}{l}\text { трудовые ресурсы } \\
\text { Конечное сальдо отражает остаток суммы затрат на } \\
\text { конец периода }\end{array}$ & Ми долями в течении срока контракта работника \\
\end{tabular}

Puc. 5. Структура синтетического счёта 27 «Затраты на трудовые ресурсы» Источник: собственная разработка

Так как в нормативной базе и литературе отсутствуют рекомендации по ведению аналитического учёта, соответствующие современным условиям применения информационных технологий и повышения требований к детализации информации в целях управления организацией. В части решения данной проблемы предлагаем в связи с вышеизложенной методикой учёта затрат на трудовые ресурсы аналитический учёт представить следующим образом:

27.1.1 затраты на обучение,

27.1.2 затраты по повышению квалификации, по участию в семинарах, конференциях,

27.1.3 затраты на переподготовку,

27.2.1 затраты на вознаграждения,

27.2.2 затраты на медицинское обслуживание,

27.2.3 затраты на оздоровление.
Рекомендуемая нами методика составления записей по управленческому учёту затрат на трудовые ресурсы представлена в таблице 1 .

Здесь мы выделяем систему счетов по учёту затрат на трудовые ресурсы для систематизации информации при подготовке управленческой и консолидированной финансовой отчётности корпораций.

Так, по счетам учёта затрат предлагаем вести аналитический учёт в соответствии с видами затрат, их целевой направленностью, наименованием структурного подразделения и источников финансирования затрат на трудовые ресурсы (рисунок 6).

Такое структурное строение счёта 27 «Затраты на трудовые ресурсы» позволит формировать информационную базу обо всех затратах организации при целевой направленности как в це-

Таблица 1. Методика учётных записей по учёту затрат на трудовые ресурсы корпораций

\begin{tabular}{|c|c|c|}
\hline \multirow{2}{*}{ Хозяйственная операция } & \multicolumn{2}{|c|}{ Корреспонденция счетов } \\
\hline & Дебет & Кредит \\
\hline \multicolumn{3}{|c|}{ Корреспонденция счетов по учету затрат на развитие трудовых ресурсов: } \\
\hline Затраты на развитие трудовых ресурсов: & 27.1 & 60 \\
\hline Затраты на обучение & 27.1 .1 & 60 \\
\hline $\begin{array}{l}\text { Затраты по повышению квалификации, по участию в семинарах, } \\
\text { конференциях }\end{array}$ & 27.1.2 & 60 \\
\hline Затраты на переподготовку сотрудников & 27.1 .3 & 60 \\
\hline $\begin{array}{l}\text { Согласно расчета ежемесячно списываются затраты на развитие } \\
\text { трудовых ресурсов }\end{array}$ & 26 & 27.1 \\
\hline $\begin{array}{l}\text { Согласно расчета ежемесячно списываются затраты на развитие } \\
\text { трудовых ресурсов сверх планируемых затрат }\end{array}$ & 90.10 & 27.1 \\
\hline \multicolumn{3}{|c|}{ Корреспонденция счетов по учету затрат на содержание трудовых ресурсов: } \\
\hline Затраты на содержание трудовых ресурсов & 27.2 & 70,60 \\
\hline Затраты на вознаграждения & 27.2 .1 & 70 \\
\hline Затраты на медицинское обслуживание & 27.2 .2 & 60 \\
\hline Затраты на оздоровление & 27.2 .3 & 60 \\
\hline $\begin{array}{l}\text { Согласно расчета ежемесячно списываются затраты на содержа- } \\
\text { ние трудовых ресурсов: } \\
\text { - сверх планируемых затрат }\end{array}$ & $\begin{array}{c}20,23,25,26 \\
90.10\end{array}$ & 27.2 \\
\hline
\end{tabular}




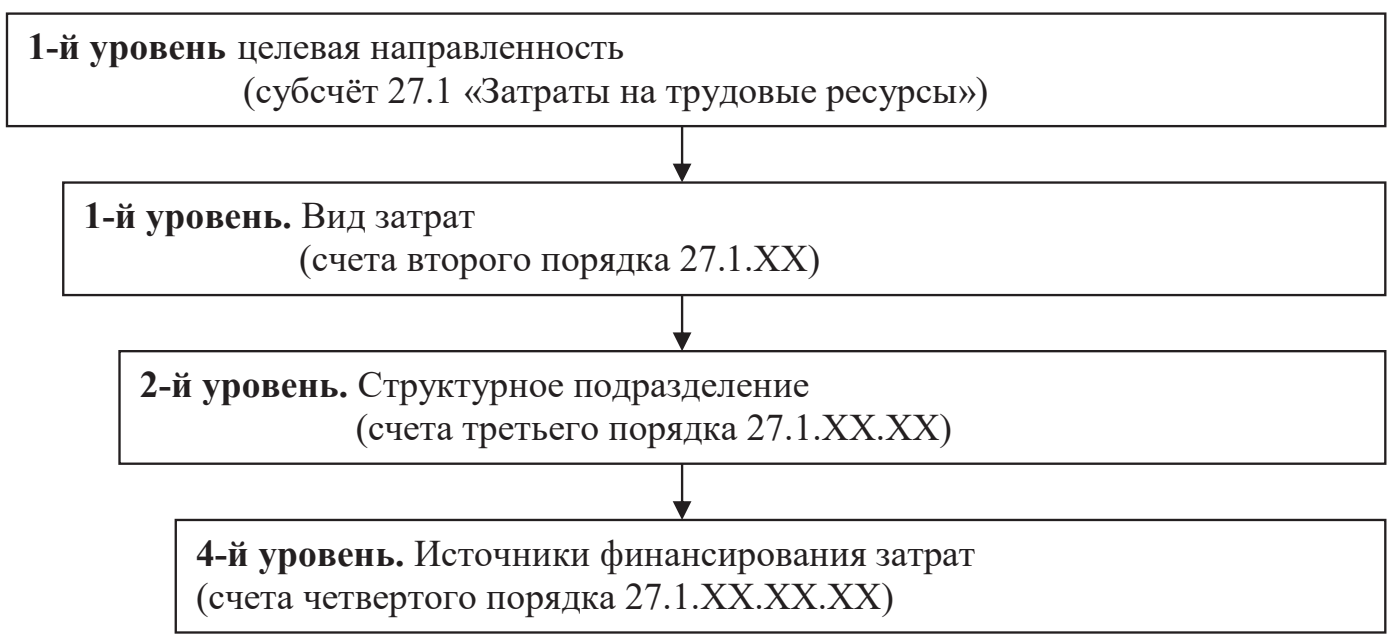

Puc. 6. Рекомендуемая система аналитического учёта затрат на трудовые ресурсы Источник: собственная разработка

лом, так и в разрезе их видов. Кроме того, учётные записи по указанным субсчетам позволят определить, на наш взгляд, фактическое использование средств организации по соответствующим направлениям.

Таким образом, вследствие выделения самостоятельного объекта учёта «затраты на трудовые ресурсы» становится возможным сбор информации о полных затратах на трудовые ресурсы в части определения эффективности средств, вкладываемых в трудовые ресурсы и принятие обоснованных управленческих решений по оптимизации данных затрат.

Предложенная нами классификация затрат на трудовые ресурсы по различным критериям позволяет учитывать все затраты на трудовые ресурсы на протяжении всего периода деятельности организации и положена в основу формирования информации о затратах на трудовые ресурсы на счетах бухгалтерского управленческого учёта. Это позволит обосновать состав затрат на трудовые ресурсы, систему управленческих счетов, методики управленческого учёта, направленных на формирование достоверной информационной базы для управленческого анализа эффективности затрат на трудовые ресурсы, а также их управленченсого аудита.

\section{Библиографический список}

1. Киевич А.В., Койпаш Д. А. Краудинвестинг как альтернативная модель финансирования инвестиционного проекта. / А. В. Киевич, Д. А. Койпаш // Экономика и банки. 2016. № 1. С. 58-65.

2. Галкина, М. Н. Методики внедрения комплаенс-контроля в системе корпоративного управления / М. Н. Галкина // Бухгалтерский учет и анализ: научно-практический журнал. - 2017. - № 8.- С. 15-21.

3. Самоховец М.П. Бюджетное финансирование социальной сферы Республики Беларусь / М.П. Самоховец, М. И. Бухтик, А. В. Киевич // Экономические науки. 2020. № 184. С. 104-109.

4. Об установлении типового плана счетов бухгалтерского учёта, утверждении Инструкции о порядке применения типового плана счетов бухгалтерского учёта, утв. Постановлением Министерства финансов Республики Беларусь от 29.06.2011 г. № 50 (в ред. от 22.12.2018 г. № 74) // Нац. реестр правовых актов Республики Беларусь.-2018. - № 8/33714.

5. План счетов бухгалтерского учёта финансово-хозяйственной деятельности организаций и инструкции по его применению: приказ М-ва финансов Российской Федерации от 31 октября 2000 г. № 94н, с изм. и доп. от 7 мая 2003 г. [Электронный ресурс]. Режим доступа: http://www1.minfin.ru/ru/accounting/accounting/ legislation

6. План счетов бухгалтерского учёта и инструкции по его применению: приказ М-ва финансов Украины от 03.10.1999 № 291. [Электронный ресурс]. Режим доступа: http://minfin.gov.ua/control/uk. 
7. Шестак, О.Н.Учёт расходов на оплату труда работников торговли и пути его совершенствования// Бухгалтерский учёт и анализ. - 2003.- № 4.- С.32-35

8. Там же

9. Трудовой кодекс Республики Беларусь от 26.07 .1999 г. № 296-3(в ред. Законов Республики Беларусь от 01 января 2015 № 238-3) // Консультант Плюс: Беларусь. Технология Проф. 3000 [Электронный ресурс] / ООО ”ЮрСпектр“, Нац. центр правовой информ. Республики Беларусь.- Минск, 2019.

10. Ситарева В. Формирование учетной политики в целях МСФО / В.Ситарева // Международные стандарты финансовой отчетности (мсфо): Производственно-практический, научный журнал. - 2019.- N 6. - С. $13-16$ 